\title{
SIMULATING CAPITAL INCOME TAXATION AND WELFARE UNDER A DSGE FRAMEWORK
}

This paper develops a dynamic stochastic general equilibrium (DSGE) model for analyzing the impact of various capital income tax policies in a small open economy populated by households possessing endogenous time preferences. We contribute to the literature by studying the impacts of: i) anticipated tax shocks under stochastically growing output, ii) stochastic tax shocks under deterministic output, on our dynamic general equilibrium framework. With our model's specifications, this is the first attempt to integrate uncertainty into the study of taxation and welfare. Our results suggest that only under certain conditions welfare paradoxes may exist, in the sense that increases in tax instruments may improve welfare.

Keywords: endogenous time preference, adjustment costs, perturbation methods, stochastic shocks

JEL Classifications: F4, E62

DOI: $10.15611 /$ aoe.2018.1.04

\section{INTRODUCTION}

"It is often said that nothing is certain in life except death and taxes. While death is undoubtedly certain, there is, in fact, considerable uncertainty with respect to tax rates" . As Sialm (2006) points out, there has been a significant fluctuation in marginal income tax rates in the United States from 1913 to $1999^{2}$, which implies that there is tax policy uncertainty.

This paper is the first attempt to include stochastic taxation in a dynamic general equilibrium framework with endogenous rates of time preference, even though there are many studies existing in both finance and public economics literature. For instance, Stiglitz (1982) discusses the welfare impacts of random taxation. According to Skinner (1988), "tax policy is often unpredictable because of factors beyond the control of government". He shows the considerable variability of tax rates in the US during the period 1929-1975. By studying the additional excess burden of uncertain tax

\footnotetext{
${ }^{*}$ Department of Economics, Middle East Technical University, Ankara, Turkey.

${ }^{1}$ Hassett and Metcalf (1999).

${ }^{2}$ This is also valid for OECD countries. For more information see the OECD tax database.
} 
policy, he computes that uncertainty in tax policy led to a $\$ 12$ billion extra burden for the US economy in 1985. In addition, Hassett and Metcalf (1999) use a model with an uncertain investment tax credit to study the effects of tax policy uncertainty on aggregate investment. They find that, under a continuous time random walk, tax policy uncertainty causes a delay in investment. This is also in line with the findings of Agliardi (2001). Yet by extending Hassett and Metcalf's (1999) model, Böhm and Funke (2000) demonstrate that the effects of tax policy uncertainty must be very limited because of various modelling assumptions.

On the other hand, recent literature on fiscal economics points towards the effects of different types of government spending versus tax shocks on GDP and its components. Alesina, Ardagna, Perotti and Schiantarelli (2002) investigate the effects of a change in fiscal policy on private investment using a panel of OECD countries. They find that taxes do have a negative impact on output, as did Blanchard and Perotti (2002). Moreover, the latter conclude that private consumption increases follow an increase in tax rates. In both these studies it is shown that any increase in taxes will crowd out private investment. In addition, Perotti (2004) points out that the impact of any change in tax policy on GDP and its components have become weaker over time. Mountford and Uhlig (2008) try to distinguish the effects of fiscal policy shocks for the US economy between 1955-2000.

It is clear from the literature that dynamic stochastic general equilibrium (DSGE) models have been gaining importance and macroeconomic theory is widely built upon these models to derive micro-founded relations. The setup of these models is straightforward. The agents are rational so that the consumers maximize their expected utility given their budget constraint, firms maximize their profits subject to the available technology and governments are required to satisfy the government budget constraint (Hebous, 2011). DSGE models are generally successful in capturing the responses of macroeconomic variables following a shock (Unal, 2015). For instance, Angelopoulos et. al (2008) study the changes in the impacts of changes in taxes on long-term growth and expected lifetime utility in the UK economy under a DSGE setup. They conclude that even though the growth effects of tax reforms are small, the welfare effects can be substantial. Similarly, Papageorgiou (2012) investigates the general equilibrium effects of fiscal policy reforms in Greece with a neo-classical growth model. Their main finding is that if the fiscal policy targets an increase in welfare by changing the tax mix, the tax rate on labour income needs to be decreased and the consumption tax rate should be increased. Incorporating a DSGE model, Kliem and Kriwoluzky (2011) employ an idea similar to the Taylor 
rule and conclude that while the Taylor type rule is not optimal, its feedback variables are the correct choice of a welfare maximizing policy maker. Examining the optimal fiscal policies in an economy with different externalities from government expenditure in a two-sector endogenous growth model, $\mathrm{Lu}$ (2015) concludes that the optimal tax rate of capital income is positive if productive public spending exists.

The objective of this paper is to contribute to the literature by focusing on the impacts of anticipated tax shocks under stochastically growing output, and stochastic tax shocks under deterministic output, in a dynamic general equilibrium framework with endogenous rates of time preference. The analysis is based on the simulations performed on the basis of a calibrated system. As pointed out above, the empirical studies indicate that tax rate changes are frequent, and, in most cases, future tax changes cannot be predicted. This basically implies that tax changes can be an element of uncertainty. For instance, since the 1990s there has been tax competition in the sense that countries cut tax rates to attract investment which makes firms operate in a tax-cut scenario because of the possibility of further future reductions. Thus, whatever the sign of the tax rate change is, tax rate uncertainty is an important issue that must be analyzed (Fedele, Panteghini, Vergalli, 2009). To put it differently, it is important to see how the agents react if there is an uncertainty about the tax levels in the economy. It is worth noting that over the last two decades most of the studies in the literature have used either real option models to study the effects of tax rate uncertainty on investment or econometric/numerical techniques to see the impact and/or international transmission of any shock in an economy. Here, we deviate from these studies by setting up a stochastic dynamic general equilibrium model to focus on the welfare effects of various capital tax instruments in a small open economy populated by infinitely-lived households possessing endogenous time preference that is in line with Epstein and Hynes (1983) ${ }^{3}$. The model also assumes that the households can borrow or lend freely in the world capital market. Perfectly competitive firms produce one good that can be used for consumption and investment which is subject to adjustment costs in the sense that the firm has to pay an installation cost. We then simulate the model and show that: (i) under a deterministic setup, a permanent expected increase in any of capital income tax will lead to a change in welfare that depends on whether the marginal productivity of capital exceeds or falls short of the real rate of interest; (ii) when output is stochastically growing, any increase in tax levels causes

\footnotetext{
${ }^{3}$ For empirical findings, see also Obstfeld (1990).
} 
a decrease in welfare regardless of where the economy stands; (iii) when there is a stochastic change in tax levels, the change in welfare will depend on the change in the type of the capital income tax, in the sense that a stochastic negative change in corporate income tax and tax on capital gains will lead to an increase in welfare because of the increase in wealth.

The model we present in the next section also predicts the effects of any change in tax levels on consumption, capital stock, shadow price of capital and the current account. Unlike most intertemporal equilibrium models, our model leads to the non-monotonic adjustment of the current account in response to various policy changes. This implies that, if adjustment costs are beyond a certain threshold, there will be an initial decrease in both savings and investment when investment is at its lowest level. Thereafter, savings will increase parallel to the low levels of disinvestment ${ }^{4}$.

There are three theoretical papers closely related to our paper in terms of the addressed questions: Bizer and Judd (1989), Nielsen and Sorensen (1991) and Karayalcin (1995). Bizer and Judd (1995) made a seminal contribution by highlighting the uncertainty in tax policy under a dynamic general equilibrium framework by implementing the Markov process. Their model is relatively straightforward since only two types of taxes (investment tax credit and income tax rate) are included.

To examine the dynamic macroeconomic effects of capital income taxation, Nielsen and Sorensen (1991) develop a small open economy with perfect mobility of financial capital as possessing time-additive (exogenous) preference. Although various forms of capital income taxation are included in the model, the changes in taxes are deterministic. Therefore, here we depart from Nielsen and Sorensen (1991) in extending the model by including both endogenous time preference and adding a stochastic framework. The former is adopted because, if the constant-discount rate does not match with the parametric world interest rate, a stationary equilibrium does not exist. On the other hand, if that rate diverges from the parametric world interest rate, the time additive preferences will cause a hysteretic adjustment towards the steady state ${ }^{5}$, rendering the analysis dependent on initial conditions.

Finally, by combining endogenous time preference and adjustment costs, Karayalcin (1995) builds a model that focuses on the welfare effects of capital tax instruments in a small open economy. In that framework, due to the adjustment costs, he ended up with a lower degree of consumption

\footnotetext{
${ }^{4}$ See Karayalcin (1994).

${ }^{5}$ See Karayalcin (1995), Sen and Turnovsky (1990).
} 
smoothing since agents will no longer be able to undertake a frictionless adjustment in the capital stock. Another significant difference is that his study concentrated on unanticipated tax shocks and their welfare effects. Here we deviate from Karayalcin (1995) in enhancing the model by involving both stochastically growing output and stochastic taxation. We also differ from all three papers cited above by incorporating numerical analysis which measures the magnitudes of effects due to the variation in capital income taxes.

The paper proceeds as follows. The next section sets up a model with stochastically growing output in a small open economy with perfect capital mobility of financial capital. The setup is one with infinitely-lived households possessing endogenous rate of time preference and adjustment costs in investment. The effects of changes in tax policy instruments will be studied in section three, and section four concludes the paper.

\section{THE MODEL}

Consider an economy that produces a single good that may be used for consumption as well as investment. For simplicity's sake, it is assumed that firms produce in a competitive market. The economy is populated by infinitely-lived households possessing endogenous time preferences. The number of households are normalized to one without loss of generality. The government collects taxes by following a balanced budget policy in the sense that the tax revenue is used to finance the households via transfers.

\subsection{Households}

The welfare of households is taken to depend on the consumption of the good in the market. Also, the households receive the wage $w_{t}$ by inelastically supplying one unit of labour services per unit of time. We denote the world interest rate by $r$, the interest income tax rate by $t_{r}$ and the household's net assets by $a_{t}$, that is the sum of the value of domestic equity and the value of foreign assets. Thus, $r\left(1-t_{r}\right) a_{t}$ is the net interest income. According to equations (1)-(3) below, the consumer maximizes the expected discounted lifetime welfare subject to the constraint that the current increase in non-human wealth is equal to the sum of after-tax income from wealth, from labour and from government transfers minus consumption.

We also adopt the endogenous rate of time preference structure proposed by Epstein and Hynes (1983). Other than the time-additive models, in this 
setting, time preference imply a well-defined long-term target level. Therefore, lifetime welfare $U$ is maximized over consumption path $C$ by

$$
U(C)=-E_{t} \sum_{t=0}^{\infty} \exp \left(-z_{t}\right) \frac{1}{1+\left(1-t_{r}\right) r},
$$

subject to

$$
\begin{gathered}
z_{t+1}-z_{t}=u\left(c_{t}\right)-r, \\
a_{t+1}-a_{t}=\left(1-t_{r}\right) r a_{t}+w_{t}-c_{t}-t_{t}, \\
z_{0}=0,
\end{gathered}
$$

where $u(c)>0$ is required to be a strictly increasing and strictly concave felicity function in the sense that $u^{\prime}>0$ and $u^{\prime \prime}<0$ and $t_{t}$ is the lump-sum government transfer.

Following Obstfeld (1990) and Epstein and Hynes (1983), one can argue that the lifetime welfare functional $U$ deviates from the time-additive utility functionals by its recursivity. As is widely known, additivity implies that the marginal rate of substitution between times $t_{1}$ and $t_{2}$ is independent of consumption at any $t \neq t_{1}, t_{2}$. However, here recursivity allows this marginal rate of substitution to be independent of consumption before $t_{1}$ but not after $t_{2}$ in order to make future consumption weakly separable from past consumption levels. Therefore, the variable rate of time preference $\Omega$ at time $s$ has the following form:

$$
\Omega_{s}=\left\{\sum_{s=v}^{\infty} \exp \left[-\sum_{s=v}^{t} u\left(c_{s}\right)\right]\right\}^{-1} .
$$

$\Omega$ at time $s$ is the following function of the utility functional $U(C)$

$$
\Omega\left(\phi_{s}\right)=-\phi_{s}^{-1}
$$

and

$$
\phi_{s}=U\left({ }_{s} C\right),
$$

where $U$ represents the positive discounting of future consumption and $\phi_{s}$ denotes aggregate future consumption (or lifetime welfare at time $s$ ). It 
should be noted that the rate of time preference is not constant as will be the case in the additive model. On the other hand, as in the steady state, if the consumption path is globally constant, $c_{t+1}=c_{t}$ for all $t$ and $c_{t}=\bar{c}$. In this case the rate of time preference is given by

$$
\bar{\Omega}(\bar{\phi})=u(\bar{c}),
$$

where the upper bars denote a long-term equilibrium.

Even though there is significant dispute on whether impatience to consume has to increase or decrease as current consumption goes up, since it is assumed that $u^{\prime}(c)>0$, in our framework increasing marginal impatience will take place as in Lucas and Stokey (1984), who basically emphasize that a kind of diminishing private returns to saving is required to have local stability. Therefore, the felicity function is specified as:

$$
u\left(c_{t}\right)=\ln c_{t}+\omega,
$$

where $\omega$ stands for a parameter to measure generalized time preference.

By using equations (1)-(4) and (9), the standard solution of the life-time welfare maximization problem yields:

$$
E_{t}\left(c_{t+1}\right)=\left[\left(1-t_{r}\right) r+1-\Omega\left(\phi_{t}\right)\right] c_{t} .
$$

On the other hand, by differentiating (1) with respect to time, we can obtain the dynamics of lifetime welfare:

$$
E_{t}\left(\phi_{t+1}\right)=1+\phi_{t}\left(u\left(c_{t}\right)+1\right) .
$$

\subsection{Firms}

Competitive firms employ capital $k_{t}$ and labour to produce the single good which is used for both consumption and investment. The production function is

$$
f\left(k_{t}\right)=\theta_{t}^{y} k_{t}^{\alpha},
$$

where $\theta_{t}^{y}$ is the aggregate productivity shock which follows a stochastic autoregressive process ${ }^{6}$ with the disturbance term $\varepsilon_{t}$ assumed to be normally distributed with mean zero and variance $\sigma_{y}^{2}$ i.e. $\varepsilon_{t} \sim N\left(0, \sigma_{y}^{2}\right)$.

\footnotetext{
${ }^{6}$ The details are provided in the next section.
} 
We assume that the firm finances a fraction $(1-\varepsilon)$ of new investment by debt issues and the remaining fraction $\varepsilon$ by retained earnings as:

$$
b_{t}^{c}=(1-\varepsilon) k_{t}
$$

and

$$
b_{t+1}^{c}-b_{t}^{c}=(1-\varepsilon)\left(k_{t+1}-k_{t}\right) .
$$

After corporate income tax is applied, the remaining profits are distributed as dividends to equity holders. Therefore, before personal tax, total dividends, $\pi_{t}$, are:

$$
\pi_{t}=\left[f\left(k_{t}\right)-w_{t}-r b_{t}^{c}-T\right]\left(1-t_{c}\right)+b_{t+1}-b_{t}-\left(1-t_{l}\right) i_{t},
$$

where $t_{c}$ and $t_{l}$ stand for the corporate income tax rate and the rate of investment tax credit, respectively, and $T$ denotes the adjustment cost. If the firm changes its capital, it is subject to adjustment costs in the sense that the firm has to pay a deadweight installation cost other than the actual cost $i_{s}$. The installation $\operatorname{cost}^{7}$ must be an increasing function of $i$ in relation to $k$, which should have the following properties:

$$
T(0)=0, \quad T^{\prime}>0, \quad 2 T^{\prime}+(i / k) T^{\prime \prime}>0 .
$$

In our framework the installation cost function is specified as $T\left(i_{t} / k_{t}\right)=(\chi / 2)\left(i_{t} / k_{t}\right)$ so that, in order to increase the capital stock by $i$ units, the representative firm needs to pay $i_{t}\left[1+(\chi / 2)\left(i_{t} / k_{t}\right)\right]$ units of output.

Foreign bonds $b_{t}^{f}$ and corporate bonds $b_{t}^{c}$ are treated to be perfect substitutes. Thus they have to pay the same expected after tax return. If $V_{t}$ denotes the market value of outstanding equity $t_{r}$ stands for the personal interest income tax rate, and $t_{g}$ is the capital gains tax rate, for all $t$, therefore the arbitrage condition will be:

$$
r\left(1-t_{r}\right)=\frac{\pi_{t}}{V_{t}}+\frac{\left(1-t_{g}\right)\left[E_{t}\left(V_{t+1}\right)-V_{t}\right]}{V_{t}},
$$

\footnotetext{
${ }^{7}$ Note that the adjustment cost depends on gross investment rather than net investment. Yet, since we ignore depreciation, these terms can be treated as the same.
} 
where the term on the left-hand side is the after tax income on foreign bonds, whereas the right-hand side delineates the after tax equity return, consisting of current yield and capital gains. The market value of equity at time zero will therefore be:

$$
V_{s}=E_{s} \sum_{s=1}^{\infty} \theta_{g_{(s)}}^{-1} \pi_{s}\left(\frac{\theta_{g}}{\theta_{g}+r \theta_{r}}\right)^{s-1},
$$

where $\theta_{i}=1-t_{j}, j=(c, g, r)$. Firms choose to maximize the present discounted value of $V_{s}$ subject to the constraint $i_{s}=k_{s+1}-k_{s}$. The solution yields:

$$
\begin{gathered}
E_{s}\left(q_{s+1}\right)=\frac{q_{s}\left(r \theta_{r}+\theta_{g}\right)}{\theta_{g}} \\
-\frac{\theta_{c}}{\theta_{g}}\left[E_{s}\left(f^{\prime}\left(k_{s+1}\right)\right)-r(1-\varepsilon)+E_{s}\left[\left(\frac{i_{s+1}}{k_{s+1}}\right)^{2} T^{\prime} \frac{i_{s+1}}{k_{s+1}}\right]\right], \\
q_{s}=\frac{1}{\theta_{g}}\left\{\left(\varepsilon-t_{l}\right)+\theta_{c}\left[T+\left(\frac{i_{s}}{k_{s}}\right)^{2} T^{\prime} \frac{i_{s}}{k_{s}}\right]\right\}, \\
w_{s}=f\left(k_{s}\right)-f^{\prime}\left(k_{s}\right) k_{s},
\end{gathered}
$$

where the shadow price of capital at time $s$ is given by $q_{s}$. Following Hayashi (1982), we can define $q_{s}$ as the ratio of market value of firm's equity to the replacement cost of capital. Thus, $q_{s}$ in equation (20) can be considered as a variant of Tobin's Q. Equation (21) is the equilibrium condition for the labour market while the law of motion for the shadow price of capital is given by (19).

Equation (20) can be used to represent the rate of investment $i_{t} / k_{t}$ as the following function of $q_{t}$ :

$$
i_{t}=k_{t+1}-k_{t}=k_{t} \gamma\left(q_{t}\right),
$$

where $\gamma^{\prime}\left(q_{t}\right)=\left(\theta_{g} / \theta_{c}\right) \chi>0$. Equation (22) simply expresses investment as an increasing function of the shadow value of capital, $q_{\mathrm{t}}$. Here, it should be noted that both $q$ and $i$ are independent of the consumption and saving decisions of the households. 


\subsection{The current account}

In this subsection, by recalling the government's balanced budget policy in order to acquire the dynamics of the current account, let us use (3), (15)(22) and $a_{t}=b_{t}^{f}+q_{t} k_{t}+b_{t}^{c}$. We therefore obtain

$$
b_{t+1}^{f}-b_{t}^{f}=r b_{t}^{f}+f\left(k_{t}\right)-i_{t}(1+T)-c_{t},
$$

which states that the increase in foreign asset holdings equals the difference between the sum of output and interest earnings of the representative household less the sum of consumption and investment expenditures.

\subsection{Characterization of the equilibrium}

It is convenient to describe the economy's steady state before characterizing the equilibrium behaviour of our model. The market clearance and optimality conditions will give the long-term relations in this economy. We can easily obtain the steady state value of the shadow price of capital $\bar{q}$ by using (19) and (22), and imposing the stationarity conditions. At a steady state

$$
\bar{q}=\frac{\varepsilon-t_{l}}{\theta_{g}}, \quad \bar{q}=q^{*}\left(t_{g}, t_{l}\right), \quad q_{1}^{*}>0, \quad q_{2}^{*}<0,
$$

where, in order to guarantee a positive value of $\bar{q}$, it is assumed that the replacement cost of capital is higher than the debt issue per unit of capital, $1-\varepsilon<1-t_{l}$, indicating that the firm does not overfinance its investment ${ }^{8}$.

Similarly, it yields ${ }^{9}$

$$
\begin{gathered}
f^{\prime}(\bar{k})=r\left[(1-\varepsilon)+\frac{\theta_{r}\left(\varepsilon-t_{l}\right)}{\theta_{c} \theta_{g}}\right], \quad \bar{k}=k^{*}\left(t_{g}, t_{c}, t_{r}, t_{l}\right), \\
k_{1}^{*}<0, \quad k_{2}^{*}<0, \quad k_{3}^{*}>0, \quad k_{4}^{*}>0, \\
r \bar{b}^{f}=\bar{c}-f(\bar{k}), \quad \bar{b}=b^{*}\left(t_{g}, t_{c}, t_{r}, t_{l}\right), \\
b_{1}^{*}>0, \quad b_{2}^{*}>0, \quad b_{3}^{*}<0, \quad b_{4}^{*}<0,
\end{gathered}
$$

\footnotetext{
${ }^{8}$ For more information, see Nielsen and Sorensen, 1991.

${ }^{9}$ The derivatives are given in the Appendix.
} 


$$
\begin{aligned}
& u(\bar{c})=r \theta_{r}, \quad \bar{c}=c^{*}\left(t_{r}\right), \quad c^{* \prime}<0, \\
& \bar{\phi}=-\left(\frac{1}{r \theta_{r}}\right), \quad \bar{\phi}=\phi^{*}\left(t_{r}\right), \quad \phi^{* \prime}<0
\end{aligned}
$$

Thus, one can obtain the steady state values of $(\bar{q}, \bar{k}, \bar{b}, \bar{c}, \bar{\phi})$, by using equations (24)-(28).

Since we do have the steady state values of all the variables, it is convenient to follow Schmitt-Grohe (2004) and solve our system by perturbation methods. Before doing so, let us briefly discuss this method. The first-order perturbation method is similar to the linearization of the Euler equations around a steady state. Essentially, with the help of the techniques for forward looking rational expectations, the linear model is solved. As one of the main requirements we need to satisfy is the Blanchard-Kahn (1980) condition, i.e. the number of roots larger than 1 in the modulus has to match the number of forward-looking variables in the model ${ }^{10}$. To put it differently, for the system to be locally saddle-path stable it has to be the case that three of the eigenvalues have to be larger than 1 in the modulus, since the system has three predetermined (backward looking) variables $\left(k, \theta^{y}, b\right)$, and three control (forward looking) variables $(c, \phi, q)$. It is simple to show that this is the case here.

\section{VARIOUS FISCAL SHOCKS AND THEIR EFFECTS ON THE ECONOMY}

In this section, we examine the outcomes of the model under different types of shocks. Before moving on to this part, although actual tax systems differ, let us define the case where $t_{g}=t_{r}$ and $t_{c}=t_{l}=0$; in other words an economy under a uniform, comprehensive income tax, no investment subsidies and with fully integrated corporation taxes. Therefore, in this case we will end up with $f^{\prime}(\bar{k})=r$ equivalence confirming the Schanz-Haig-Simons result which argues for the neutrality of income tax with respect to investment.

Yet in a real-world tax system, $\bar{q}$ and $\bar{k}$ will be affected by tax factors because generally neither the investment tax credit is equal to zero, nor is the

\footnotetext{
${ }^{10}$ For details, see Judd (1996 and 1998), Sims (2002), Kim and Kim (2003), Schmitt-Grohe and Uribe (2004) and Collard and Juillard (2001).
} 
effective tax rate on interest earnings less than the tax rate on accrued capital gains. Thus, there occurs a distortionary wedge between the global interest rate and the marginal productivity of capital in the home country, i.e. $r \neq f^{\prime}(\bar{k})$. Suppose, initially, that the former exceeds the latter. In this case, any policy that shrinks the home capital stock will, by increasing its marginal productivity, reduce the distortion and raise lifetime welfare. Thus in order both to analyze our model more concretely and to investigate the outcomes of different scenarios more profoundly, two countries, Canada and Sweden, are included. Among our countries, Canada represents the $f^{\prime}(\bar{k})<r$ case, whereas Sweden embodies the $f^{\prime}(\bar{k})>r$ case given the initial values. Several countries, including the other OECD countries, are taken for this exercise. However, from among those, Canada and Sweden were the only two that satisfied the aforementioned conditions ${ }^{11}$.

\subsection{Deterministic tax shocks and their effects on welfare}

Since the welfare effect is going to play an important role in the next section, in order to be able to compare and contrast, we will start out from considering the effects of an expected permanent increase in the corporate income tax rate. As seen in equation (25), this will reduce the long-term capital stock of the economy and therefore the effect on consumption on impact will be positive. However, since the long-term foreign asset holdings increase, an increase in savings is expected as well, which causes a negative effect on consumption on-impact. The net effect is determined by the initial condition of the economy, i.e. $f^{\prime}(\bar{k})>r$ or $f^{\prime}(\bar{k})<r$. Following Karayalcin (1995), we can infer that $\phi$ on-impact yields the present discounted value of the future felicity stream as of time $t=0$. Thus, the difference between $\phi$ on-impact and initial $\bar{\phi}$ is a measure of the welfare effects of the policies under consideration. To summarize, if, initially $f^{\prime}(\bar{k})>r$, we can expect a drop in consumption on-impact so will lifetime welfare because the decline in capital stock caused by the rise in $t_{c}$ will accentuate the distortion by increasing the marginal product of capital.

Figures 1-4 show the simulation results for an increase in $t_{c}$ and $t_{g}$ both for Canada and Sweden. We find that under an expected permanent increase

\footnotetext{
${ }^{11}$ See Appendix B for more information.
} 
in the corporate income tax or tax on capital gains, lifetime welfare increases in Canada, whereas Sweden will suffer from the rise in taxes due to the reasons mentioned above. To place the discussion in a familiar setting, let us examine the Canadian, $f^{\prime}(\bar{k})<r$ case. An expected permanent rise in corporate income $\operatorname{tax}^{12}$ will cause an increase in welfare. This is mainly because of the required long-term decrease in the domestic capital stock and the long-term increase in foreign asset holdings; see equations (25) and (26). If the interest earned on foreign bonds $r$ is less than the long-term effect of the decline in the capital stock on income (i.e. $f^{\prime}(\bar{k})<r$ ), the decrease in the capital stock caused by the rise in $t_{c}$ will reduce the distortion and increase lifetime welfare ${ }^{13}$.

Let us turn to the effects of an increase in the investment tax credit. As seen in equation (26), there will be a decrease in long-term foreign asset holding and a rise in the long-term capital stock because of the decline in the replacement cost of capital for both countries. Thus, for Canada, the distortion will be accentuated and there will be a decrease in welfare on impact as seen in Figures 5-6. On the other hand, since $f^{\prime}(\bar{k})>r$ holds for Sweden, the lifetime welfare will increase because of the reduction in the distortion.

Finally, we will consider the effects of a rise in the tax rate on interest income $t_{r}$. Such a policy will make ownership of real capital more attractive relative to the ownership of bonds. Thus, an increase in the longterm level of capital and a decrease in the steady state level of foreign asset holdings are expected. It should also be noted that the increase in $k$ will take place until the equity price returns to its initial level ${ }^{14}$. As can be seen in Figure (8), lifetime welfare increases in Sweden because of the rise in capital stock which will lead to reducing the distortion. On the other hand, as the increase in the tax rate discussed above indicates, if initially $f^{\prime}(\bar{k})<r$ holds, the same policy will accentuate the distortion and reduce lifetime welfare.

\footnotetext{
${ }^{12}$ The same result is valid for the tax on capital gains.

${ }^{13}$ On the other hand, if $f^{\prime}(\bar{k})>r$ initially holds, an increase in $t_{c}$ will give rise to a fall in capital stock which will accentuate the distortion and reduce lifetime welfare.

${ }^{14}$ The details are given in the next section.
} 


\subsection{Mixed shocks and the model}

In this subsection ${ }^{15}$, we begin with analyzing the model only under a stochastic productivity shock and considering that model as the benchmark. Thereafter the shocks will be mixed in the sense that the stochastic productivity shock will be kept while the anticipated permanent tax shocks will be added to see how the model reacts if agents began to expect higher tax rates.

In a stochastic framework, since the model needs to be made stationary around a steady state, permanent shocks cannot be placed. Moreover, shocks can only hit the system today and the expectation of future shocks has to be zero. However, by adding a latent shock variable $\varepsilon_{t}$ (which has a normal distribution with zero mean), it is possible to make the effect of the shock disperse slowly throughout the economy. Here, basically $\varepsilon_{t}$ is going to affect the model's true exogenous variable $\theta_{t}^{y}$ that is itself an $\operatorname{AR}(1)$ process (Griffoli, 2007):

$$
\theta_{t}^{y}=\rho \theta_{t-1}^{y}+\varepsilon_{t} .
$$

Our results suggest that under stochastically growing output, any increase in tax level will worsen the economy and reduce welfare regardless of whether $f^{\prime}(\bar{k}) \leq r$. For both countries the results are in Tables 1 and 2 and the impulse response analyses can be seen in Figures 11-18.

We first discuss the simulation results when there is only a stochastic productivity shock. Figure 9 shows the results for Canada and Figure 10 for Sweden. For both countries our indicators show a similar trend in adjustment path when hit by a stochastic productivity shock. A $1 \%$ standard error increase in $\varepsilon_{t}$ causes an increase in capital as well as consumption in the short run. The former is caused by the increase in the marginal product of capital whereas the latter is the result of an increase in output. On the other hand, there will be an increase in the rate of return on equity which leads to an immediate jump in the price of equity $q$. This will also stimulate investment by causing a current account deficit. Since $c$ jumps on impact as well, domestic absorption will increase, which deteriorates the current account deficit in the short run. However, in the long run, investment starts

\footnotetext{
${ }^{15}$ It should be noted that the same stochastic productivity shock remains throughout this part although its level is kept small in order to avoid any outweighing effect in the sense that productivity shock never dominates the tax shock. Thus, this must be considered while evaluating the results.
} 
to decrease along with the decrease in $q$ which causes an improvement in the current account balance. In addition, consumption adjusts much faster than the investment level. Thus, the accentuating effect of consumption on current account will die out or to put it differently, the current account balance will improve in the long run by adjusting non-monotonically.

Next, as discussed above, we will mix the stochastic productivity shock and anticipated permanent tax shocks. Let us start the analysis of Table 1 from considering the effects of a foreseen rise in the corporate income tax rate under stochastic productivity shocks. Suppose the government announces that a corporate tax will be implemented at time $t=20$. Anticipating a future reduction in the rate of return on equity, investors will decrease their demand for equity which will cause a drop in the price of equity $q$ on impact along with a process of capital decumulation. It should be noted that, considering equation (22), as $q$ remains below its long-term level along the adjustment path, investment will decrease (see Figures 11-12). In the short run, the decline in the rate of investment along with the reduction in consumption will improve the current account balance. Yet, in the long run, investment will increase to reach its long-term value in addition to a decline in savings that leads to a deterioration in the current account balance as in Figures (11) and (12). Therefore, the current account will adjust non-monotonically.

Under a stochastic productivity shock, a foreseen increase in capital gains tax rate $t_{g}$ will increase long-term foreign asset holdings and reduce the long-term domestic capital stock as well as lead to a rise in the long-term equity price $q$. Notice that the long-term changes in $k$ and $q$, by putting opposing pressures on impact, determine the short-term adjustment of $q$. Although there is a jump in $q$ on impact, there will follow a process of capital decumulation or, to put it differently, a decrease in investment occurs because of the increase in $t_{g}$ which clearly outweighs the jump in $q^{16}$. Afterwards, the capital stock will adjust to its new long-term level by giving rise to an increase in real investment. On the other hand, consumption drops on impact by strengthening the improving effects of the decreasing investment on the current account. Thus, the current account will have an upward trend until the increasing effects of higher savings die out. Afterwards, the current account surplus starts to decrease along with an increase in investment and adjusts to its new steady-state level (see Figures 13-14).

\footnotetext{
${ }^{16}$ See equation (35) in Appendix A.
} 
Conversely, under stochastic productivity shocks, an anticipated future increase in $t_{l}$ has an expansionary long-term effect because the investment tax credit decreases the effective price of new capital goods relative to initial capital. Therefore, the long-term level of $k$ will increase, whereas there will be a decline in the steady state level of foreign asset holdings. As in the case of an increase in $t_{g}$, there will be opposing pressures on the equity price $q$ (see Figures 15-16). On the other hand, a foreseen future tax credit is expansionary from the time it is expected until the time it takes effect. This is because of the foreseen reduction in the effective price of new capital goods. As is well-known, a higher rate of investment tax credit makes new capital cheaper relative to initial capital. Thus, there will be an increase in the domestic capital stock up until the implementation of the new tax policy. To summarize, analyzing Figures 15 and 16, we can say that capital stock per capita is increasing from the time of announcement of the new tax policy until the time it takes effect, whereas a contraction occurs after the new tax policy is introduced. On the other hand, as opposed to the case of an increase in $t_{g}$, we see an immediate jump in consumption on-impact which will aggravate the domestic absorption, worsening the current account deficit. As the economy starts to increase its holdings of foreign assets (right after implementing the new tax levels), it has to run a current account surplus which implies a nonmonotonic adjustment of the current account balance.

Finally, let us examine the effects of a foreseen rise in the personal interest income tax rate $t_{r}$ under a stochastic productivity shock. Note that an anticipated rise in the tax rate on interest income will lead to a higher demand for equity since there will be a reduction in the rate of return on foreign bonds. The excess stock demand for equity will be eliminated by an immediate jump in the price of $q$ on impact. As a result, real investment will rise as $q$ remains above its long-term level. Yet as capital intensity rises, we see that its marginal product declines up until $q$, and the rates of investment go back to their long-term values. On the other hand, since a rise in $t_{r}$ will reduce the long-term utility target, households will reduce their long-term consumption. As a consequence, the current account balance will deteriorate because of the rise in both investment and consumption levels. However, consumption will reach its steady state value sooner, and therefore the accentuating effects of higher consumption on the current account will disappear in parallel to the reduction in investment. Thus again there occurs a non-monotonic adjustment of the current account balance.

Finally, we will highlight the impacts of any changes in tax levels under stochastically growing output on welfare. Since the logic is, mutatis mutandis, the same for the rest of the exercises, we will examine the effects 
of an increase in the tax rate on capital gains and investment tax credit. As seen in Table 2, an increase in tax rate on capital gains will lead to a decrease in the long-term domestic capital stock and an increase in foreign asset holdings. Because of the reasons discussed in the previous part, this change in tax level is expected to give rise to a reduction in lifetime welfare if, initially $f^{\prime}(\bar{k})>r$. On the other hand, there will be an increase in welfare if $f^{\prime}(\bar{k})<r$ initially holds. However here, for both of the countries, consumption drops on impact and so will lifetime welfare because of the uncertainty and the risk averse utility function ${ }^{17}$. As in our model, when the effects of output shocks propagate over time, a risk averse utility function will lead to a cost called the cost of uncertainty ${ }^{18}$. That is mainly why we ended up with the following: it is clear from Tables 1 and 2 that on-impact consumption levels (and lifetime welfare) are lower than the benchmark cases. On the other hand, an increase in the investment tax credit has an expansionary long-term effect on domestic capital stock and a contractionary long-term effect on foreign asset holdings. Therefore, a reduction in life-time welfare is expected for Canada whereas a rise in life-time welfare is anticipated for Sweden. However, in this case, although there is a jump on impact, life-time welfare is reduced for both of the countries - when compared to the benchmark - regardless of where the economy stands. For instance, the on-impact value of $\phi$ is -14.75 and -16.92 for Canada and Sweden respectively (see Table 1). Yet, as a response to a change in various type of tax instruments, in none of the cases we are able to have a higher $\phi$ on impact value. Thus, under stochastically growing output, a welfare paradox does not exist.

\subsection{The stochastic tax shocks and their effects}

In this part we will put the model to work by considering the effects of stochastic tax shocks ${ }^{19}$. With the following structure, we assume that the economy has been experiencing a deterministic tax structure and expects it to last forever. Then we change the tax policy by introducing some uncertainty but keeping the mean tax rate constant after an initial decrease in

\footnotetext{
${ }^{17}$ Risk aversion simply implies that individuals strictly prefer to take the expected value of a lottery to than the lottery itself.

${ }^{18}$ See Obstfeld (1994).

19 Throughout this part, productivity parameter is normalized to one without loss of generality. In other words, productivity is constant.
} 
tax levels. For this purpose we have $\delta$ 's such that $\delta_{t}^{i}=\theta_{j} e^{z_{t}}$ where $j=(c, g, l, r)$ and $z_{t}$ is the tax shock which follows a stochastic autoregressive process $z_{t}=\mu z_{t-1}+\zeta_{t}$ with the disturbance term $\zeta_{t}$ assumed to be normally distributed with mean zero and variance $\sigma_{z}^{2}$ i.e. $\zeta_{t} \sim N\left(0, \sigma_{z}^{2}\right)$. As in the case of stochastic productivity shock discussed above, similarly here we do shock the system today by dispersing its effect slowly throughout the economy. It is worth noting that an increase in $\delta_{t}^{i}$ on impact means a reduction in tax levels. Thus, throughout this part, the shocks hitting the system today are negative tax shocks.

Let us start by considering the effects of a stochastic change in the corporation tax. On impact, this will increase dividends and the rate of return on equity. The expectations of capital gains will rise and there will be an immediate jump in the price of equity $q$ leading to an immediate increase in investment which will cause a current account deficit ${ }^{20}$. Since $c$ jumps on impact, we will end up with an increase in domestic absorption which accentuates the current account deficit in the short run. Moving towards a steady state, this process reverses and continues until the rate of return on foreign bonds equals the rate of return on equity. In other words, right after an initial jump in $q$, investment starts to decrease along with the shrinking in $q$ which causes an improvement on the current account balance. Moreover, consumption adjusts much quicker, or to put it differently, the accentuating effect of higher consumption on the current account will disappear. Therefore in the long run, that will improve the current account balance as well besides the shrinking in investment.

Next we consider the effects of a stochastic change in the capital gains tax. As opposed to the previous case, here we can see is an initial drop in $q$ along with an increase in domestic capital stock. We can explain this situation by combining ${ }^{21}$ equations (18) and (19). Depending on the corresponding equation, a decrease in capital gains tax rate $\theta_{g}$ will lead to a decrease in $q$ on impact. However, although we expect (and also see) an increase in investment level, here $q$ declines. This situation can be explained by equation (22) which basically indicates that the change in $\theta_{g}$ outweighs the decline in $q$ and therefore, even though $q$ drops on impact, there is an

\footnotetext{
${ }^{20}$ It should also be noted in Figure 19 that $k$ rises/declines as soon as $q$ exceeds/falls behind its steady state value.

${ }^{21}$ The corresponding equation is given in the Appendix.
} 
increase in the investment level. In the short run, an increase in the rate of investment along with an increase in consumption will deteriorate the current account balance. On the other hand, in the long run the accentuating effect of $c$ on the current account will disappear in addition to the decrease in investment that leads to an improvement in the current account balance as seen in Figure 20.

Conversely, a stochastic change in investment tax credit causes a jump in $q$ on impact. Yet, here investment is decreasing in the short run which can be explained by equation $(20)^{22}$. It is clear in the equation that we will end up with a decrease in investment level at least in the short run because the change in $t_{l}$ has a dominating effect on the increase in $q$. Therefore, $k$ goes up in the medium-term. However, since the shock on $t_{l}$ dies out over time, towards a steady state the increase in $q$ offsets the change in investment tax credit which will give rise to an increase in $k$ (so will investment). The decrease in investment, along with declining consumption, will improve the current account balance in the short run. However, in the long run, consumption will adjust before the domestic capital stock. Thus the improving effect of higher savings on the current account will disappear in conjunction with the increase in investment level causing a deterioration in the current account balance. Again, this implies a nonmonotonic adjustment of the current account (see Figure 21).

Finally, let us consider the effects of a stochastic change in the tax rate on personal interest income. It should be noted that initially the rate of return on foreign bonds will increase. On impact, there will be a decrease on demand for equity which will be absorbed by an immediate drop in the price of equity which increases the yield on it. In the medium term, the investment will decrease due to the reduction in domestic capital stock. Therefore, the marginal productivity of capital will decrease up until the equity price $q$ and the investment levels will reach their initial levels in the long run. On the other hand, since there is a drop in consumption on impact and a decrease in the rate of investment in the short run, the current account balance will improve. However, again, that process reverses in the long run, indicating a deterioration in the current account balance before it reaches its long-term level or, to put it differently, an implication of a non-monotonic adjustment of the current account.

Next we will briefly point out the welfare impacts of stochastic tax changes. As seen from Figures (19)-(22), while a stochastic change in

\footnotetext{
${ }^{22}$ Also see Appendix A.
} 
corporate income tax and the tax rate on capital gains cause an increase in consumption on impact (so will welfare), a stochastic change in investment tax credit and the tax rate on personal interest income lead to a drop in welfare. Here, since long-term values do not change, we need to provide an alternative explanation. As is known, wealth is roughly equal to $q k$. Thus, an increase in wealth level will give rise to an increase in consumption level which will also cause an increase in welfare. For instance, it is obvious from Figure 19 that, as a response to a stochastic corporation tax shock, both $k$ and most of the time $q$, remain above their steady-state levels that make individuals wealthier and lead to a rise in consumption. On the other hand, the opposite holds for a stochastic interest income tax shock (see Figure 22). As a response to a capital gains tax shock, while $k$ stays above its long-term level because of the reasons explained above, $q$ is below its steady state level. Here we can conclude that the increase in domestic capital stock, $k$, outweighs the decline in $q$. Thus, consumption increases since there is an increase in wealth level ${ }^{23}$.

\section{CONCLUSION}

In this paper we have examined the dynamic macroeconomic effects of different capital income taxation methods in a model of a small open economy with endogenous recursive time preferences and adjustment costs in investment where perfectly competitive firms produce one good that can be used for consumption and investment. We have shown the adjustment paths of consumption, lifetime welfare, equity prices, current account and investment in response to various tax shocks. Our results suggest that welfare paradoxes may exist only under deterministic output and anticipated tax shocks. Unlike most intertemporal equilibrium models, our model leads to the nonmonotonic adjustment of the current account in response to various policy changes.

Our model can be generalized in numerous ways. For instance, it is worthwhile to generalize to see the outcomes of any change in tax policy or, in other words, how the tax policy might be adjusted in an economy. It may also be interesting to enhance our analysis by allowing the households to supply their labour elastically to study the impact of tax policy changes on wages and consumption. Our model can also be extended to a two-country framework to analyze the international transmission of shocks.

${ }^{23}$ Again, the opposite holds for a stochastic investment tax credit shock. 


\section{REFERENCES}

Agliardi, E., Taxation and Investment Decisions: A Real Option Approach, "Australian Economic Papers", 40, pp. 44-55, 2001.

Alesina, A., Ardagna, S., Perotti, R., Schiantarelli, F., Fiscal Policy, Profits and Investment, “American Economic Review”, 92 (3), pp. 571-589, 2002.

Angelopoulos, K., Malley, J., Philippopoulos, A., Tax Structure, Growth and Welfare in the UK. Working Paper. Available at: http://www.gla.ac.uk/media/media_68955_en.pdf, 2008.

Bizer, D., Judd, K. L., Taxation and Uncertainty, “American Economic Review, 79 (2), pp. 331-336, 1989.

Blanchard, O., Kahn, C., The Solution of Linear Difference Models under Rational Expectations, "Econometrica", 45, pp. 1305-1311, 1980.

Blanchard, O., Perotti R., An Empirical Characterization of the Dynamic Effects of Changes in Government Spending and Taxes on Output, "Quarterly Journal of Economics" 177, pp. 1329-1368, 2002.

Böhm, H., Funke, M., Optimal Investment Strategies under Demand and Tax Policy Uncertainty. CESifo Working Paper No. 311, 2000.

Collard, F., Juillard, M., Accuracy of Stochastic Perturbation Methods: The Case of Asset Pricing Models, "Journal of Economic Dynamics and Control", 25, pp. 979-999, 2001.

Epstein, L., Hynes, A., The Rate of Time Preference and Dynamic Economic Analysis, "Journal of Political Economy", 91, pp. 611-635, 1983.

Fedele, A., Panteghini, P.,Vergalli, S., Optimal Investment and Financial Strategies under Tax Rate Uncertainty. Discussion Paper No. 0912, 2009.

Griffoli, T. M., Dynare User Guide: An Introduction to the Solution and Estimation of DSGE Models. Manuscript, 2007.

Hassett, K. A., Metcalf, G. E., Investment with Uncertain Tax Policy: Does Random Tax Policy Discourage Investment? "Economic Journal”, 109 (457), pp. 372-393, 1999.

Hayashi, F., Tobin's Marginal and Average q: A Neoclassical Interpretation, "Econometrica", 50, 213-224, 1982.

Hebous, S., The Effects of Discretionary Fiscal Policy on Macroeconomic Aggregates: A Reappraisal, „Journal of Economic Surveys”, 25(4), pp. 674-707, 2011.

Judd, K., Approximation, Perturbation, and Projection Solution Methods in Economics, [in:] Handbook of Computational Economics. North Holland, 1996.

Judd, K., Numerical Methods in Economics. MIT Press, Cambridge, MA, 1998.

Karayalcin, C., Adjustment Costs in Investment, Time Preferences, and the Current Account, "Journal of International Economics", 37, 81-95, 1994.

Karayalcin, C., Capital Income Taxation and Welfare in a Small Open Economy, "Journal of International Money and Finance", 14, pp. 785-800, 1995.

Kim, J., Kim, S. H., Spurious Welfare Reversals in International Business Cycle Models, "Journal of International Economics", 60, pp. 471-500, 2003. 
Kliem, M., Kriwoluzky, A., Sarferaz, S., On the Long-Run Implications of US Public Debt, working paper. Available at: https:/www.ifk-cfs.de/fileadmin/downloads/events/ jls/Kliem_et_al_FINAL.pdf, 2011

Lu, C. H., Optimal Fiscal Policies in an Economy with Externalities from Public Spending, "Journal of Economics", 116, pp. 211-228, 2015.

Lucas, R., Stokey, N., Optimal Growth with Many Consumers, "Journal of Economic Theory", 32, pp. 139-171, 1984.

Mounford, A., Uhlig, H., What Are the Effects of Fiscal Policy Shocks? NBER Working Paper Series 14551, 2008.

Nielsen, S., Sorensen, P., Capital Income Taxation in a Growing Economy, "European Economic Review”, 34, pp. 179-197, 1991.

Obstfeld, M., Intertemporal Dependence, Impatience and Dynamics, "Journal of Monetary Economics, 26, pp. 45-75, 1990.

Obstfeld, M., Evaluating Risky Consumption Paths: The Role of Intertemporal Substitutability, "European Economic Review", 38, pp. 1471-1486, 1994.

Papageorgiou, D., Fiscal Policy Reforms in General Equilibrium: The Case of Greece, "Journal of Macroeconomics", 34 (2), pp. 504-522, 2012.

Perotti, R., Estimating the Effects of Fiscal Policy in OECD Countries. CEPR Working Paper no. 276, 2004.

Schmitt-Grohe, S., Uribe. M., Solving Dynamic General Equilibrium Models Using a Secondorder Approximation to the Policy Function, "Journal of Economic Dynamics and Control", 28, pp. 755-775, 2004.

Sen, P., Turnovsky, S., Investment Tax Credit in an Open Economy, "Journal of Public Economics", 42, pp. 277-299, 1990.

Sialm, C., Stochastic Taxation and Asset Pricing in Dynamic General Equilibrium, "Journal of Economic Dynamics and Control”, 30, pp. 511-540, 2006.

Sims, C., Solving Linear Rational Expectations Models, "Computational Economics", 20, pp. 1-20, 2002.

Skinner, J., The Welfare Cost of Uncertain Tax Policy, "Journal of Public Economics”, 37 (2), pp. 129-145, 1988.

Stiglitz, J. E., Utilitarianism and Horizontal Equity: The Case for Random Taxation, "Journal of Public Economics" 18 (1), pp. 1-33, 1982.

Unal, U., Rethinking the Effects of Fiscal Policy on Macroeconomic Aggregates: A Disaggregated SVAR Analysis, "Romanian Journal of Economic Forecasting", 18 (3), pp. 120-135, 2015.

Received: September 2014, revised: March 2017

Acknowledgement: I would like to thank Veysel Avsar, Sheng Guo, Cem Karayalcin, Mihaela Pintea and Peter Thompson for helpful discussions. 


\section{Appendix A. Derivatives}

The derivatives in (24)-(28) are as follows:

$$
\begin{gathered}
q_{1}^{*}=\frac{\left(\varepsilon-t_{l}\right)}{\theta_{g}^{2}}>0, \quad q_{2}^{*}=-\frac{1}{\theta_{g}}<0, \\
k_{1}^{*}=\frac{r \theta_{r}\left(\varepsilon-t_{l}\right)}{\theta_{c} \theta_{g}^{2} f^{\prime \prime}(\bar{k})}<0, \\
k_{3}^{*}=\frac{r\left(\varepsilon-t_{l}\right)}{-\theta_{c} \theta_{g} f^{\prime \prime}(\bar{k})}>0, \quad k_{2}^{*}=\frac{\theta_{g} k_{1}^{*}}{\theta_{c}}<0, \\
b_{1}^{*}=-\frac{f^{\prime}(\bar{k}) k_{1}^{*}}{r}>0, \quad k_{2}^{*}=-\frac{r \theta_{r}}{-\theta_{c} \theta_{g} f^{\prime \prime}(\bar{k})}>0, \\
b_{3}^{*}=-\left[\bar{c}+\frac{f^{\prime}(\bar{k}) k_{3}^{*}}{r}\right]<0, \quad k_{2}^{*}>0, \\
c^{*}=r \bar{c}, \\
\phi^{*}=-\left(\frac{1}{r \theta_{r}^{2}}\right) .
\end{gathered}
$$

The aforementioned equations are as follows:

For section 3.2

Plugging adjustment cost equation into equation (20) and transforming the obtained one yields:

$$
i_{t}=k_{t}\left(\frac{\theta_{g}(q-\bar{q})}{\chi \theta_{c}}\right) \text {. }
$$

For section 3.3

$$
q_{0}=E_{t} \sum_{t=0}^{\infty}\left(\frac{1}{1+\frac{r \theta_{r}}{\theta_{g}}}\right)^{t} \frac{\theta_{c}}{\theta_{g}}\left[f^{\prime}\left(k_{t+1}\right)-r(1-\varepsilon)+\left[\left(\frac{i_{t+1}}{k_{t+1}}\right)^{2} T^{\prime} \frac{i_{t+1}}{k_{t+1}}\right]\right]
$$


If capital gains tax rate decreases, $\left(\frac{1}{1+\frac{r \theta_{r}}{\theta_{g}}}\right)^{t}$ will increase which means an increase in $q_{o}$. On the other hand, $q_{o}$ will decline because of the decrease in $\frac{\theta_{c}}{\theta_{g}}$. Thus, we can conclude that the latter impact dominates the former.

Once the adjustment cost equation is plugged into equation (20), after some transformations we will end up with the following:

$$
\frac{i_{t}}{k_{t}}=\frac{\theta_{g} q_{t}-\varepsilon+t_{l}}{\chi \theta_{c}} .
$$

As investment tax credit declines $t_{l}$ investment level will decrease. On the other hand, the increase in $q$ will stimulate investment. From Figure (21) one can infer that the impacts of the decrease in $t_{l}$ dominates the effects of the decrease in $q$ on investment level in the short run. However, it should be noted that the shock is temporary and dies out over time. Thus, after a certain point, the change in $q$ is outweighed by giving rise to an increase in investment as seen in the figure.

\section{Appendix B. Parameters}

To calibrate the model, we chose the parameters conforming to the best practice in the literature so that we have that following initial values: $r=0.04, \alpha=0.33, \rho=0.9, \mu=0.9, w=0.8, \chi=2.9$.

The country specific tax rate data is obtained from the OECD Tax Data Base as follows:

Table B. 1

Tax rate data and relevant calculations

\begin{tabular}{l|r|r|r|r|r|r|r|r}
\hline & $t_{r}$ & $t_{c}$ & \multicolumn{1}{c|}{$t_{g}$} & $t_{l}$ & $f^{\prime}\left(k^{*}\right)$ & \multicolumn{1}{c}{$r$} & $c$ & \multicolumn{1}{c}{$\phi$} \\
\hline Canada & 0.32 & 0.36 & 0.31 & 0.205 & $\mathbf{0 . 0 4 3}$ & $\mathbf{0 . 0 4}$ & 2.89 & 706 \\
\hline Sweden & 0.48 & 0.28 & 0.30 & 0.102 & $\mathbf{0 . 0 3 6}$ & $\mathbf{0 . 0 4}$ & 2.73 & 1016 \\
\hline
\end{tabular}

Source: OECD Tax Database, http://www.oecd.org/tax/tax-policy/tax-database.htm. 


\section{Appendix C: Tables and figures}

Table 1

Foreseen tax shocks under stochastically growing output and their impacts (Sweden)

\begin{tabular}{l|c|c|c|c|c|c|c}
\hline A rise in & $\bar{c}$ & $\bar{\varphi}$ & $\bar{q}$ & $\bar{k}$ & $\bar{b}$ & $c^{+}$ & $\phi^{+}$ \\
\hline $\mathrm{t}_{\mathrm{c}}$ & 0.4587 & -48.07 & 0.9285 & 25.98 & -61.78 & 0.4405 & -60.46 \\
\hline $\mathrm{t}_{\mathrm{g}}$ & 0.4587 & -48.07 & 0.9352 & 26.18 & -61.96 & 0.4054 & -84.17 \\
\hline $\mathrm{t}_{\mathrm{l}}$ & 0.4587 & -48.07 & 0.9000 & 27.29 & -62.98 & 0.4960 & -22.93 \\
\hline $\mathrm{t}_{\mathrm{r}}$ & 0.4585 & -49.01 & 0.9285 & 26.95 & -62.67 & 0.4713 & -40.76 \\
\hline \multicolumn{6}{l}{ Benchmark for Sweden } \\
\hline
\end{tabular}

Note: + above a variable indicates on-impact value for the parameter

Source: author's calculations.

Table 2

Foreseen tax shocks under stochastically growing output and their impacts (Canada)

\begin{tabular}{l|c|c|c|c|c|c|c}
\hline A rise in & $\bar{c}$ & $\bar{\varphi}$ & $\bar{q}$ & $\bar{k}$ & $\bar{b}$ & $c^{+}$ & $\phi^{+}$ \\
\hline $\mathrm{t}_{\mathrm{c}}$ & 0.4617 & -36.76 & 0.7971 & 23.58 & -59.4 & 0.4408 & -46.07 \\
\hline $\mathrm{t}_{\mathrm{g}}$ & 0.4617 & -36.76 & 0.8092 & 23.54 & -59.36 & 0.4122 & -58.79 \\
\hline $\mathrm{t}_{\mathrm{l}}$ & 0.4617 & -36.76 & 0.7681 & 24.95 & -60.73 & 0.4855 & -26.20 \\
\hline $\mathrm{t}_{\mathrm{r}}$ & 0.4615 & -37.30 & 0.7971 & 24.33 & -60.14 & 0.4822 & -28.25 \\
\hline \multicolumn{7}{l}{ Benchmark for Canada } \\
\hline
\end{tabular}

Note: + above a variable indicates on-impact value for the parameter

Source: author's calculations.

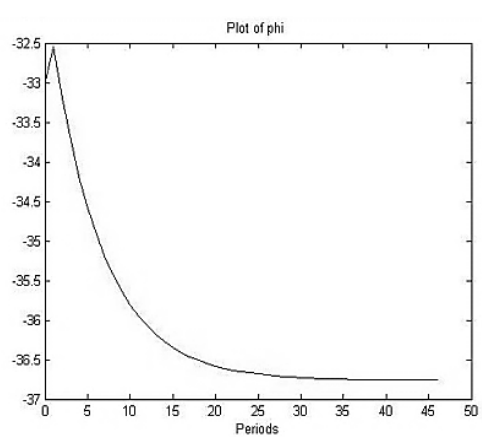

Figure 1. The welfare effect of a $3 \%$ increase in corporate income tax for Canada

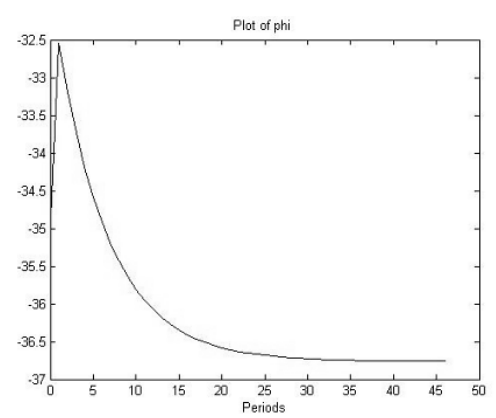

Figure 2. The welfare effect of a $3 \%$ increase in capital gains tax for Canada 


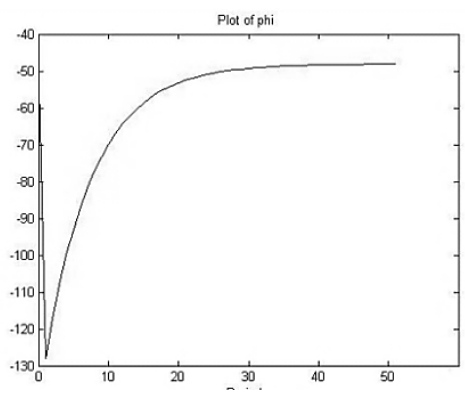

Figure 3. The welfare effect of a $3 \%$ increase in corporate income tax for Sweden

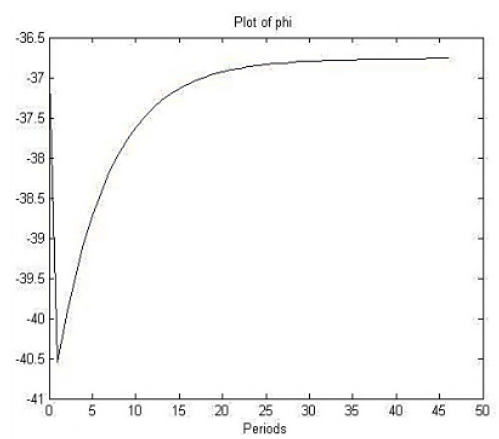

Figure 5. The welfare effect of a $3 \%$ increase in investment tax credit for Canada

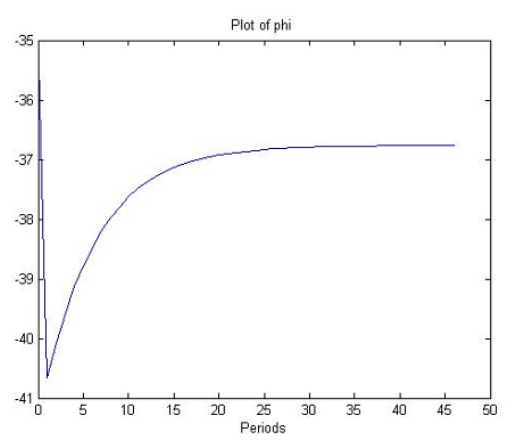

Figure 7. The welfare effect of a $3 \%$ increase in interest income tax for Canada

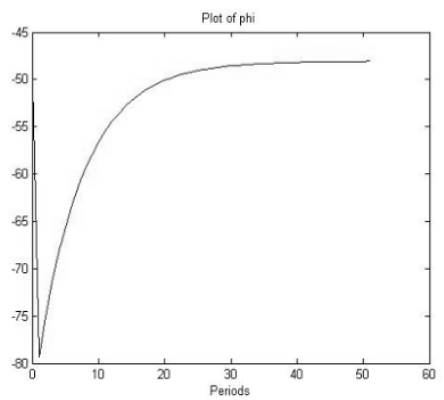

Figure 4. The welfare effect of a $3 \%$ increase in capital gains tax for Sweden

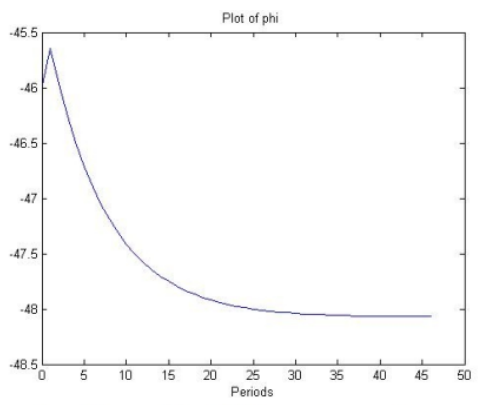

Figure 6. The welfare effect of a $3 \%$ increase in investment tax credit for Sweden

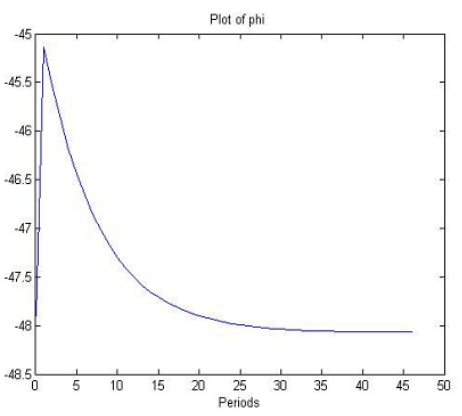

Figure 8 . The welfare effect of a $3 \%$ increase in interest income tax for Sweden 

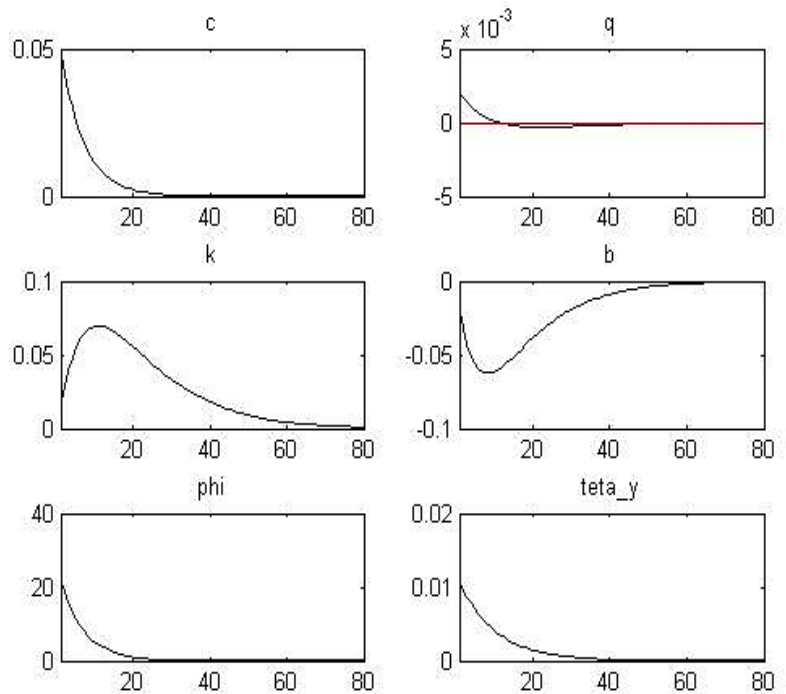

Note: The figure depicts the deviations from a steady state

Figure 9. Impulse responses following a stochastic productivity shock for Canada
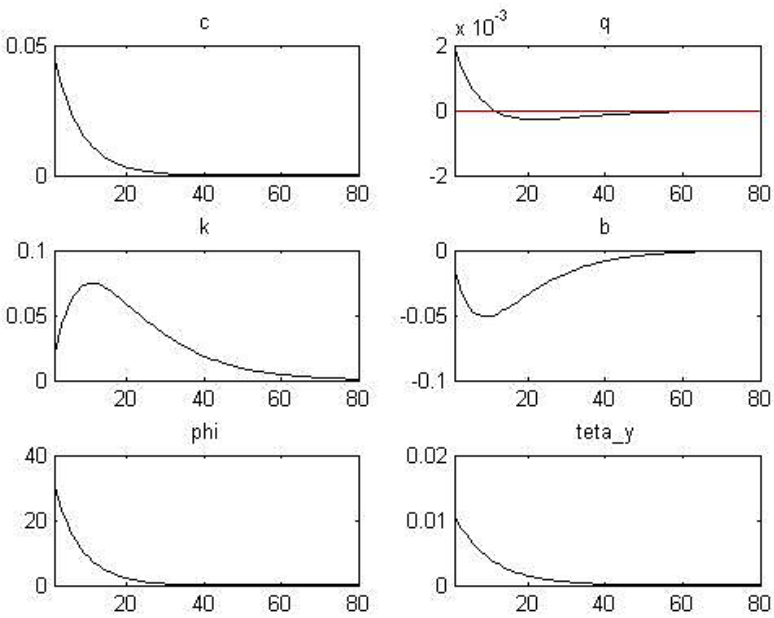

Note: The figure depicts the deviations from a steady state

Figure 10. Impulse responses following a stochastic productivity shock for Sweden 

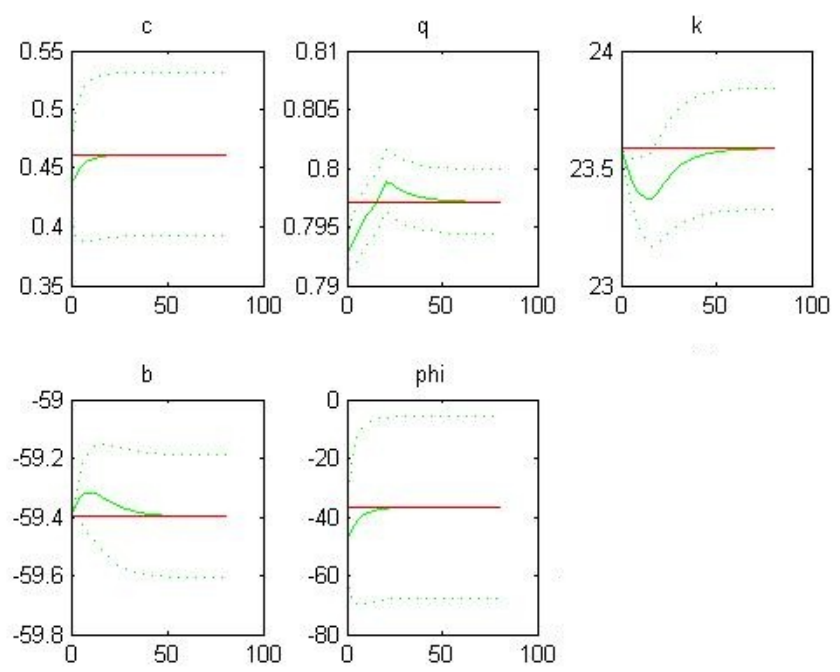

Note: Dotted lines indicate a 90\% confidence interval around the mean trajectory

Figure 11 . The effects of an anticipated $1 \%$ increase in $t_{c}$ under stochastically growing output for Canada
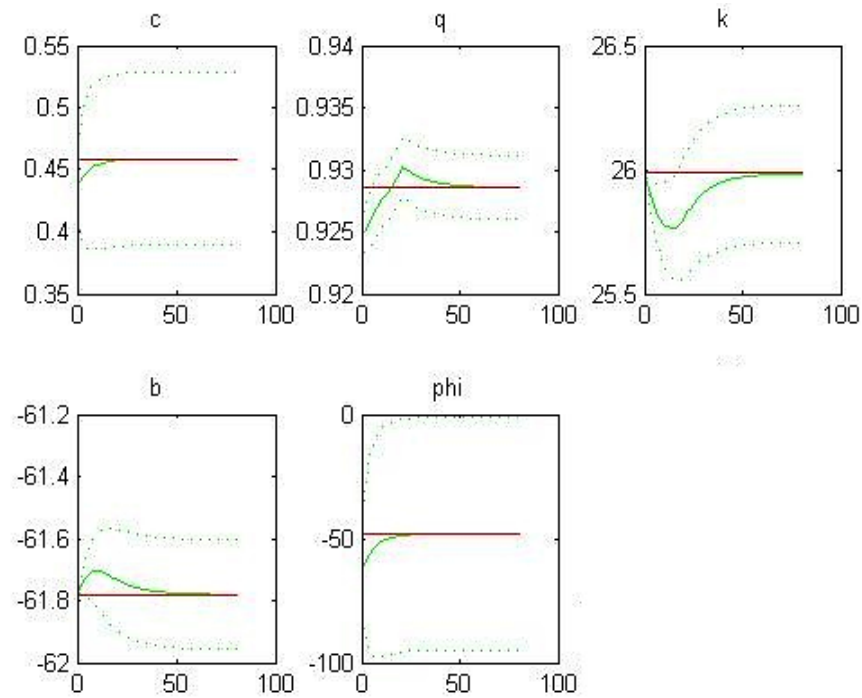

Figure 12 . The effects of an anticipated $1 \%$ increase in $t_{c}$ under stochastically growing output for Sweden. 

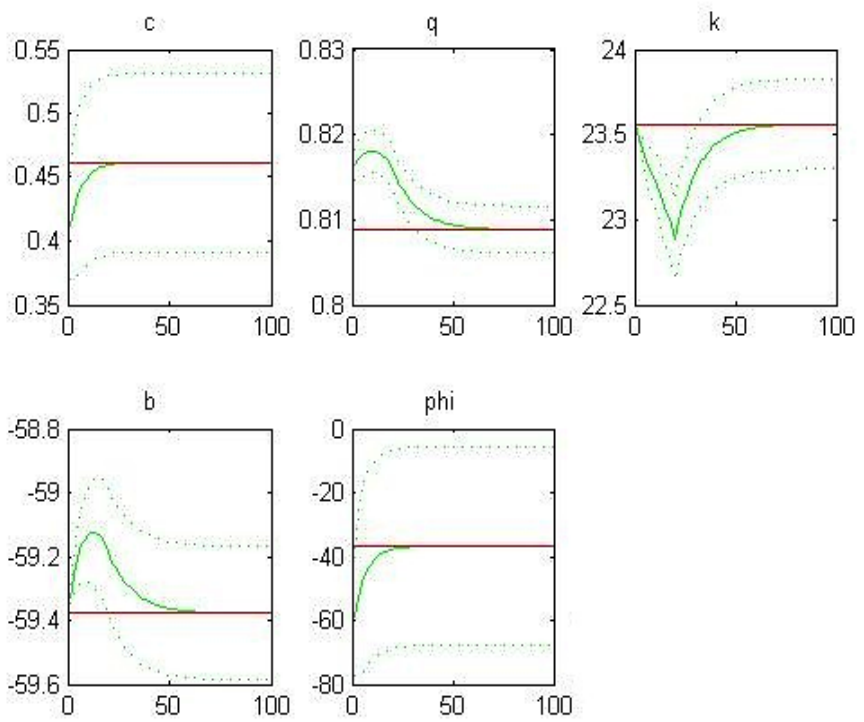

Figure 13. The effects of an anticipated $1 \%$ increase in $t_{g}$ under stochastically growing output for Canada.
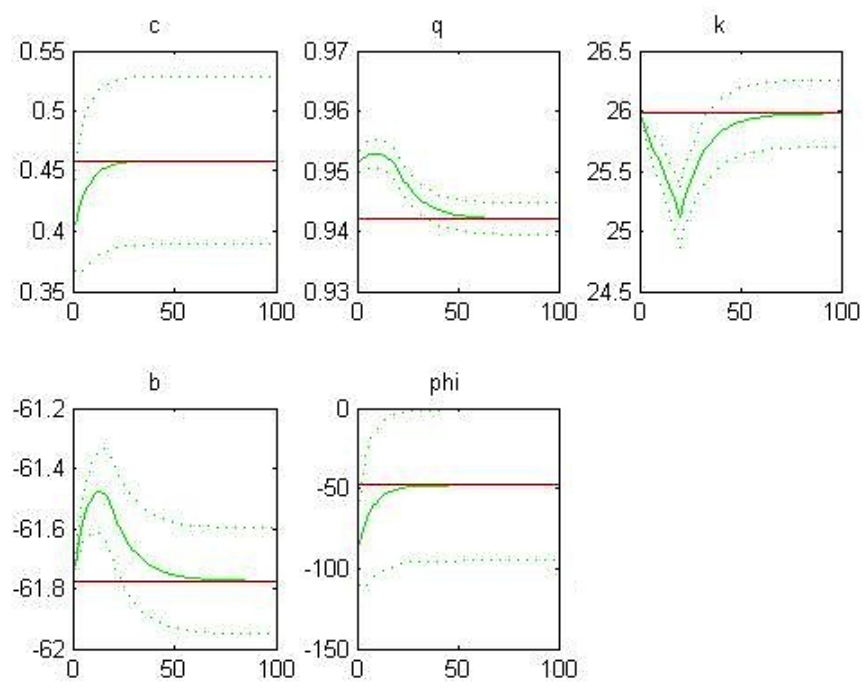

Figure 14 . The effects of an anticipated $1 \%$ increase in $t_{\mathrm{g}}$ under stochastically growing output for Sweden. 

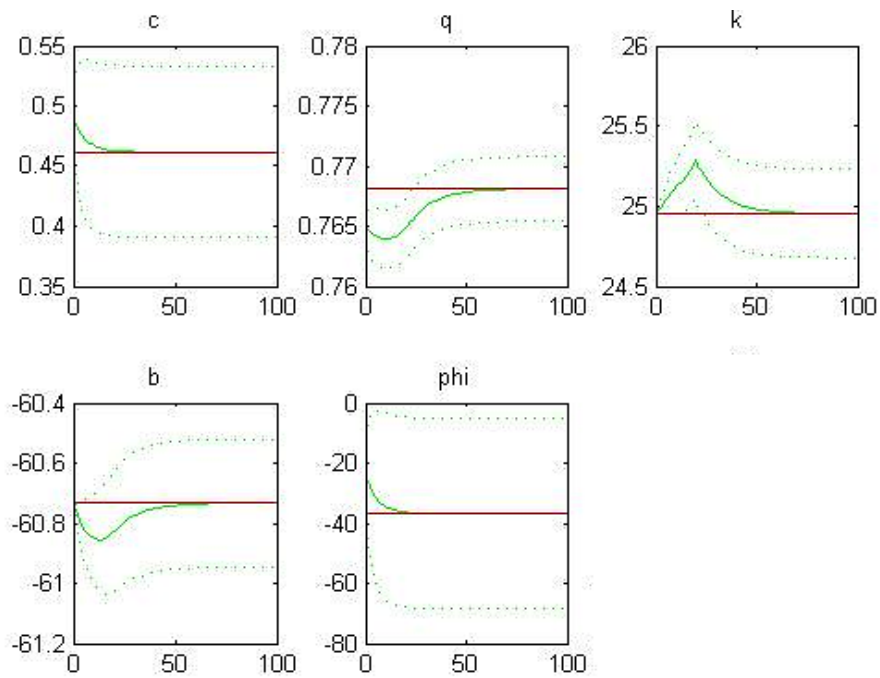

Figure 15 . The effects of an anticipated $1 \%$ increase in $t_{l}$ under stochastically growing output for Canada.
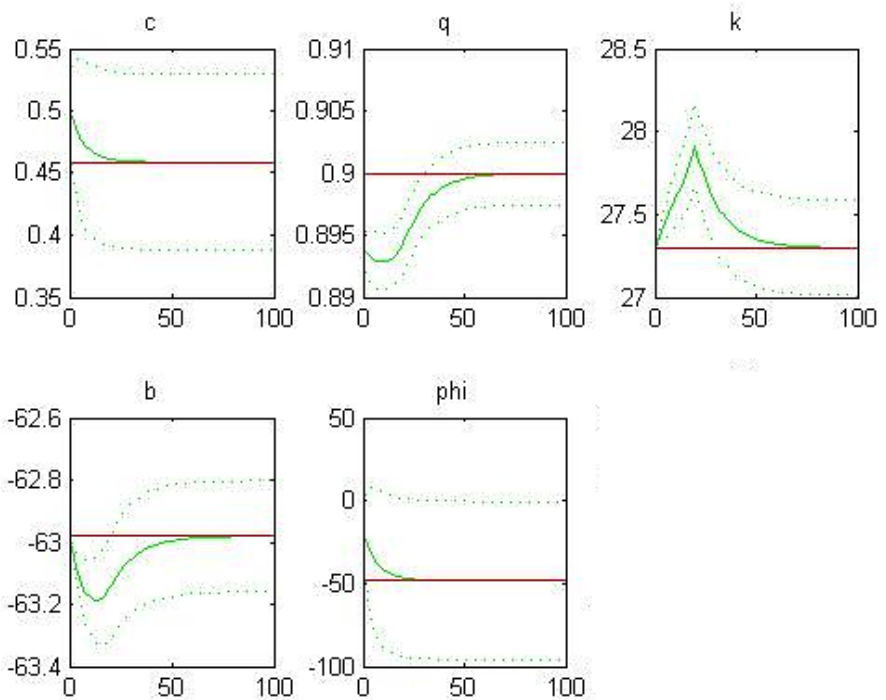

Figure 16 . The effects of an anticipated $1 \%$ increase in $t_{1}$ under stochastically growing output for Sweden 

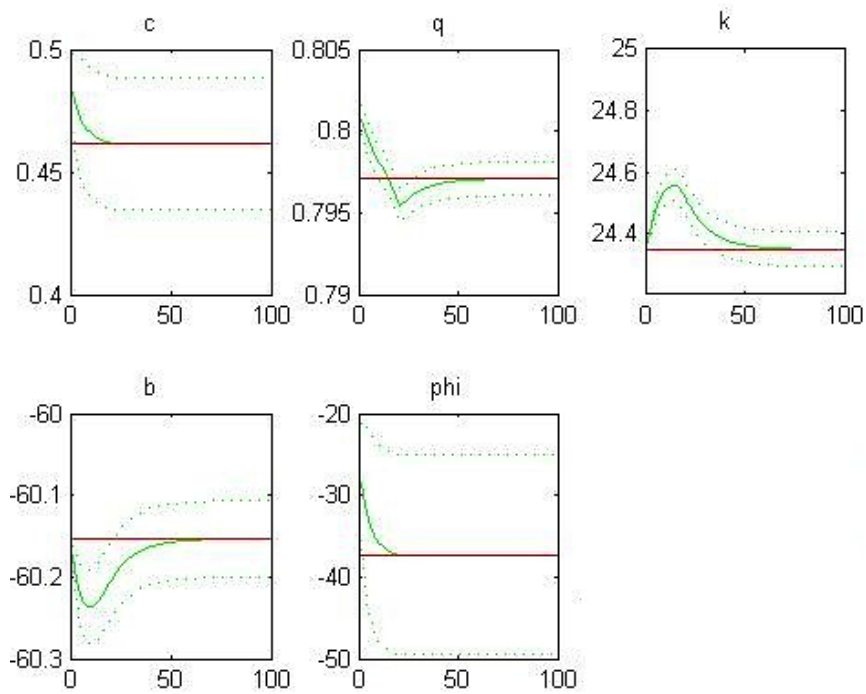

Figure 17 . The effects of an anticipated $1 \%$ increase in $t_{r}$ under stochastically growing output for Canada
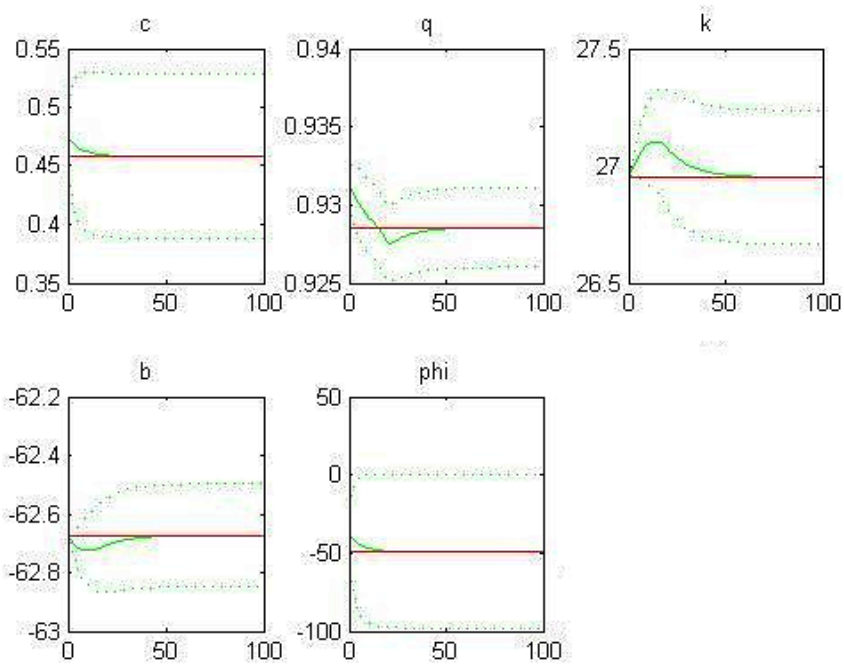

Figure 18 . The effects of an anticipated $1 \%$ increase in $t_{r}$ under stochastically growing output for Sweden. 

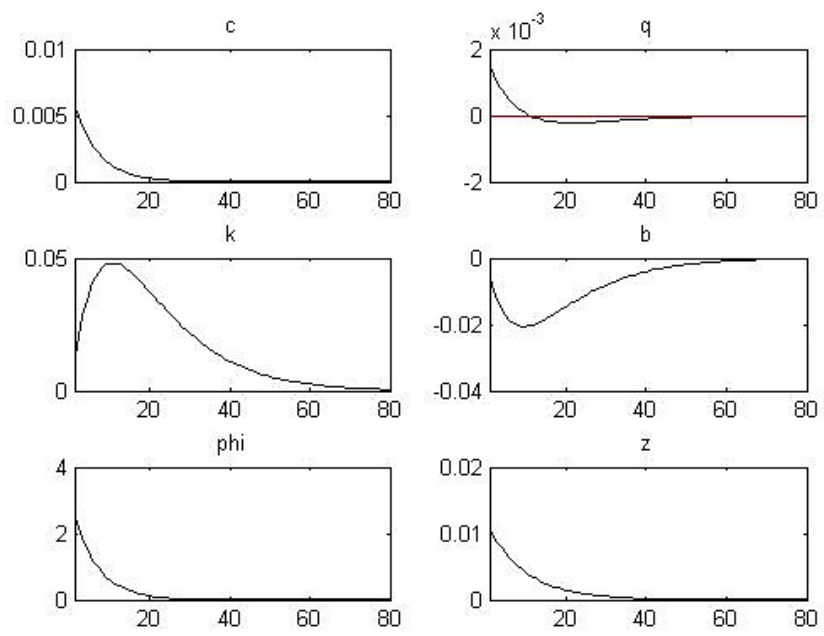

Note: The figure depicts the deviations from a steady state

Figure 19. Impulse responses following a stochastic corporation tax shock
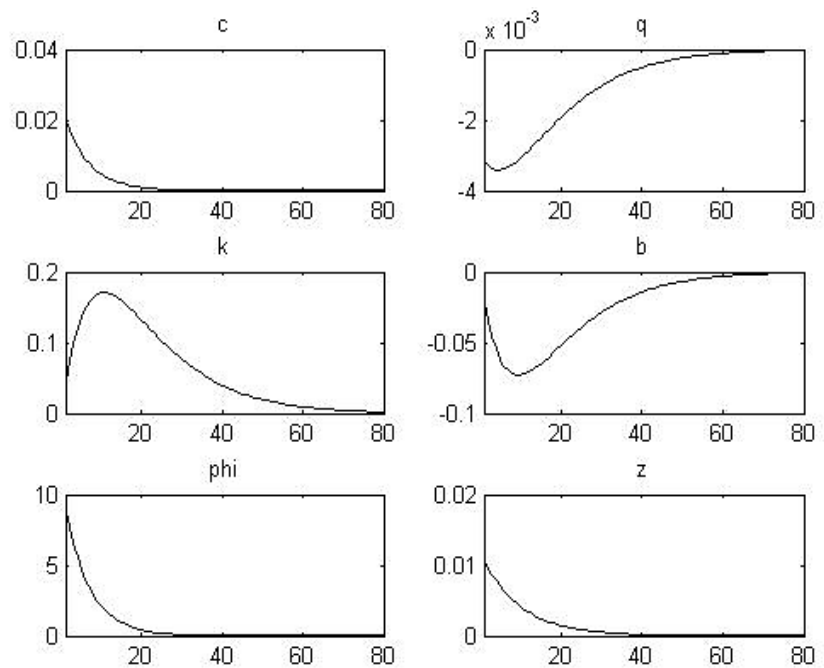

Note: The figure depicts the deviations from a steady state

Figure 20. Impulse responses following a stochastic capital gains tax shock 

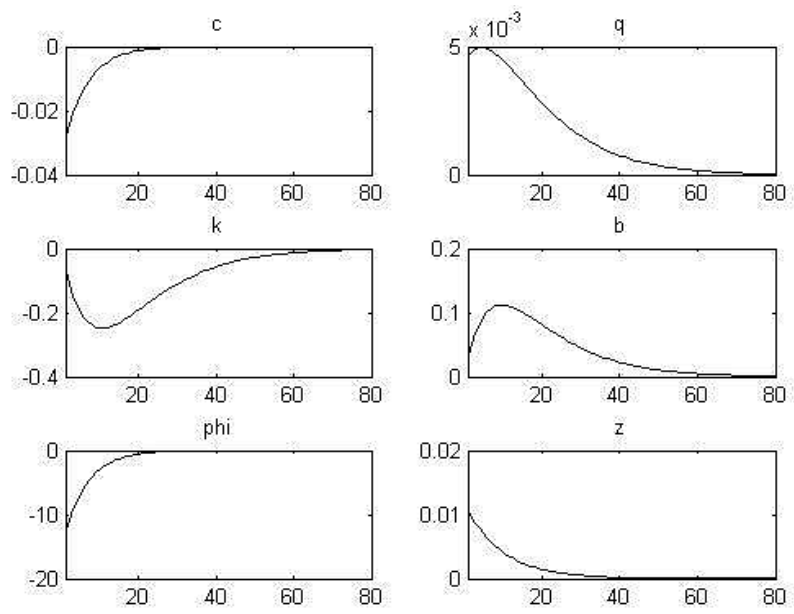

Note: The figure depicts the deviations from a steady state

Figure 21. Impulse responses following a stochastic investment tax credit shock
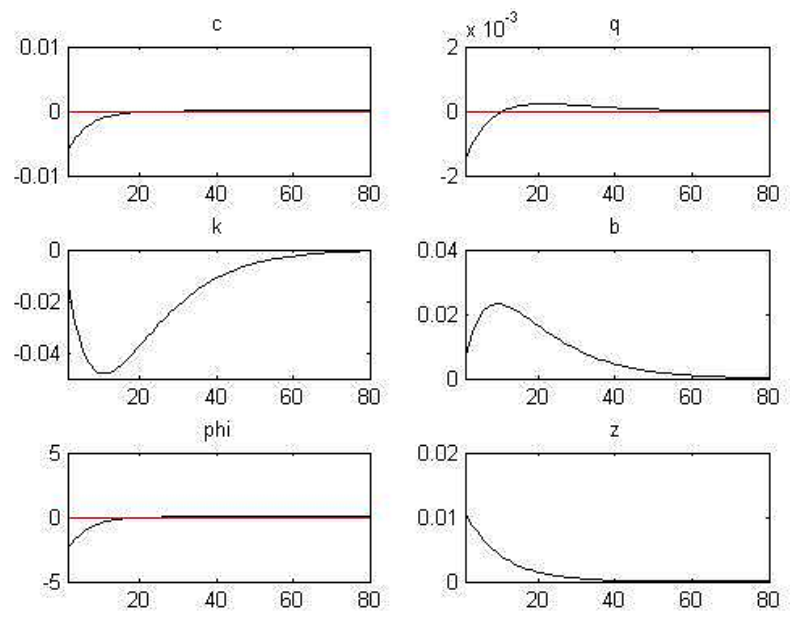

Note: The figure depicts the deviations from a steady state

Figure 22. Impulse responses following a stochastic interest income tax shock 